\title{
The undergraduate fee and enrolment decisions facing Australian universities from
}

2005.

\section{Ross Guest*}

Griffith University

\begin{abstract}
This paper presents an economic framework for analysing the undergraduate fee and enrolment decisions facing Australian universities after the legislative reforms that are due to take effect from 2005. The fee/enrolment problem is expressed both algebraically and diagrammatically in terms of the standard microeconomic concepts of marginal cost, demand, marginal revenue, and linear constraints on output and price. This conventional economic framework yields several insights. First, the government-imposed quota on fee-paying places is shown to be undesirable on efficiency grounds and argued to be undesirable on equity grounds. Second, given that universities are concerned about student quality, a drop in demand for a degree program does not necessarily imply a lower optimal level of student fees. Third, it can be optimal for the university to offer full fee places even though it is not charging the maximum premium on its HECS places.

$\underline{\text { Address for correspondence }}$

Ross Guest Professor of Economics

Graduate School of Management

Griffith University

PMB 50

Gold Coast Mail Centre

Queensland, 9726

Australia

\footnotetext{
* The author is grateful to Bruce Chapman and Glenn Withers, from the Australian National University, for their helpful comments.
} 


\section{The undergraduate fee and enrolment decisions facing Australian universities from}

2005.

\section{Introduction}

In December 2003, the Australian Parliament passed legislation that will change the way undergraduate education in Australia is funded from 2005. In order to understand these changes, it will be helpful to outline the existing system of funding undergraduate education in Australian universities.

Since 1989 students ${ }^{1}$ have been required to pay a contribution toward their tuition costs. If they pay "up front” - that is, on enrolment - they receive a 20 percent discount. The alternative is to defer payment, thereby forfeiting the discount and incurring a debt which is indexed at the rate of consumer price inflation. This debt must be repaid once the student's income reaches a threshold. The repayments are in the form of an income tax surcharge. This scheme is called HECS (Higher Education Contribution Scheme); and the amount of the student contribution is often called the HECS charge or simply HECS. The number of places which the universities can offer to students under the HECS scheme are called HECS places and for each of these places the government pays the universities an amount intended to cover the remainder of the tuition fees not covered by the HECS charge.

Australia was the first country to introduce such an income contingent loan scheme for financing higher education; and it has since been either adopted or recommended in many other countries including the UK, New Zealand, South Africa, Chile and the U.S. The scheme has also been recommended by the World Bank for implementation is Thailand, Hungary, Ethiopia and Rwanda (Chapman, 2004).

In addition, universities in Australia have been permitted to charge unrestricted fees to a maximum number of students equal to 25 percent of their total undergraduate enrolments.

\footnotetext{
1 "Students" in this paper will refer to undergraduate students, who are the group most significantly affected by the new legislation. The funding of postgraduate is largely deregulated already.
} 
These fee-paying students have not, however, been eligible for a government loan. Consequently, very few students have taken up the offer of one of these fee-paying undergraduate places.

The most important changes to this system embodied in the new legislation are:

(i) undergraduate students can pay their fees by taking out income contingent loans repayable through the income tax system, in the same way as they finance the existing HECS charges;

(ii) there is a cap on the number of students to which these fees can be charged, being no more than $35 \%$ of the total enrolment in a course, but there is no limit on the level of the fee;

(iii) universities will negotiate with the Australian Government to provide a certain number of HECS places in a discipline; and the total number across all disciplines can be varied only insofar as the Government's funding support does not increase by more than $1 \%$ or decrease by more than $5 \%$;

(iv) universities will be able to raise the student charge on HECS places by up to 25\% of the standard HECS charge for that discipline and offer discounts of up to $100 \%$ of the standard charge. ${ }^{2}$

The university will have to make a number of decisions each year. It must determine, in negotiation with the Government, the number of HECS-funded places in each discipline cluster. It must then decide the level of HECS premium or discount applying to each discipline cluster. Then, the university must determine how many additional places to offer on a full fee-paying basis and the level of the fee. This decision also depends on the minimum cut-off score it is prepared to accept in order to maintain a desired quality of its students. These decisions amount to decisions about price (fee and HECS premium/discount),

\footnotetext{
${ }^{2}$ No HECS premium can be levied on places in teaching or nursing.
} 
enrolment level, and student quality (cut-off score); in other words they are decisions about price, quantity and quality.

The aim of this paper is to provide an economic framework that helps the university and other stakeholders (students and their parents, other taxpayers and employers) think about the university’s price and enrolment decisions. To make the analysis tractable, while still drawing out some important insights, a number of simplifying assumptions are maintained throughout:

- The number of HECS places is given as a starting point. That is, there is no attempt to model the negotiations with the Government about the number of HECS places in a given discipline cluster. In practice this is a complex decision in which the university must balance the expected impact of its HECS places in a given discipline on enrolments in other disciplines. It is assumed that these negotiations have taken place.

- There exists for each discipline a bottom-line cut-off entry score below which the university is not prepared to admit students. This minimum entry score reflects the minimum level of student quality that the university deems to be acceptable in a given degree program.

- The university seeks only to maximise its operating surplus; it therefore does not have any “equity” objectives.

\section{The optimal fee and enrolment decision.}

Once the quota of HECS-funded places has been filled the university can offer full fee-paying places equal to no more than $35 \%$ of the total enrolment in the program, where the total enrolment equals HECS-funded places plus full fee places. ${ }^{3}$ Let $\mathrm{H}$ be the number of HECS-

\footnotetext{
${ }^{3}$ The HECS quota applies to a discipline which could encompass a cluster of programs, whereas the rule about maximum fee places applies to program and courses (or subjects). Here it is effectively assumed that places are allocated uniformly across programs and courses within a discipline. This avoids the complication of modelling the decision to shuffle places between courses and programs within a discipline cluster.
} 
funded places, the choice of which is exogenous to the subsequent fee and total enrolment decision. Let $\mathrm{E}$ be the total actual enrolment of undergraduate places. The maximum enrolment, $E^{\max }$, is given by $H+0.35 E^{\text {max }}$; therefore $E^{\max }=H /(1-0.35)$. Given that the minimum enrolment, $\mathrm{E}^{\mathrm{min}}$, is simply $\mathrm{H}$, the actual enrolment level $\mathrm{E}$ must satisfy

$H \leq E \leq \frac{H}{1-0.35}$

In the provision of $\mathrm{E}$ undergraduate places, let $\mathrm{R}=$ =revenue, $\mathrm{C}=$ total (opportunity) costs, and $\pi=$ profit or surplus. Therefore

$\pi=R-C$

Let $\mathrm{x}=$ actual HECS charge and HECS ${ }^{*}=$ standard HECS charge set by government, then the government-imposed constraint on the HECS charge is represented as $x \leq 1.25$ HECS $^{*}$

Let $f$-the fee charged on enrolments above the HECS quota, $H$. Therefore $R=x H+f(E-H)$

The marginal revenue from providing an additional fee-paying place is

$$
\frac{\partial R}{\partial E}=f\left(1+\frac{1}{e_{E-H}}\right)
$$

where $e_{E-H}$ is the price elasticity of demand for a place at the enrolment level of E-H. We will assume that the range $\mathrm{E}-\mathrm{H}$ is small enough that the elasticity is approximately constant over that range. That is, we will take $e_{E-H}$ as a constant, $e$ (dropping the subscript). This implies, using the formula for a constant elasticity (inverse) demand curve:

$$
f=\left(\frac{E-H}{A}\right)^{1 / e}
$$


where $\mathrm{A}$ is a positive parameter in the demand function. ${ }^{4}$

The joint fee/enrolment decision depends on both the strength of student demand and the costs of providing the places. Costs refer to full opportunity costs. The marginal opportunity cost (MC) of providing an undergraduate place is equal to the value of the best foregone alternative use of the resources used to provide that place. At the margin, undergraduate places in a given program take resources away from other undergraduate programs, postgraduate programs and research activity. These resources include academic staff time, support staff time, and physical resources including classroom space and library space. The highest valued alternative activity that is displaced by an additional undergraduate place is the marginal cost of that place. Up to a certain point, these marginal costs can be expected to decline with increasing undergraduate numbers as more efficient use is made of resources that are better suited to undergraduate places, such as lecture theatres. Beyond that point, however, increases in undergraduate places will tend to draw resources that are increasingly better suited to alternative activities. For example, the best research staff may be required to teach more undergraduate students; and the quality of postgraduate teaching and support may decline. As this occurs the MC of increasing undergraduate numbers will begin to increase.

The process of declining and then rising marginal costs describes the standard Ushaped MC curve, which is represented by the quadratic functional form:

$\frac{\partial C}{\partial E}=\alpha E^{2}+\beta E+\delta$

where $\alpha, \delta>0, \quad \beta<0$.

\footnotetext{
${ }^{4}$ The formula for a constant elasticity demand curve is $q=A p^{e}$, where $\mathrm{q}$ is output, $\mathrm{p}$ is price, A is a parameter and e is price elasticity (see for example, Varian , 1999, p.279).
} 
In order to maximise the profit on undergraduate places the university must provide the number of fee places, E-H, that equates the marginal revenue with the marginal cost, subject to the government-imposed constraint (1).

Equating (5) and (7) and substituting for $f$ from (6) yields

$$
\left(\frac{E-H}{A}\right)^{1 / e}\left(1+\frac{1}{e}\right)=\alpha E^{2}+\beta E+\delta
$$

This is a non-linear equation in E that can be solved by numerical methods. The resulting value for E can then be substituted back into (6) to obtain the solution value of $f$.

This explains how the profit-maximising enrolment level and fee could be found in principle. In practice, it would require estimates of: the three parameters in the marginal cost function, the constant elasticity of demand, $e$, in the range $\mathrm{E}-\mathrm{H}$, and the parameter, $\mathrm{A}$, in the constant elasticity demand function. This is a tall order. But simulations could be performed with combinations of plausible values of the parameters. Universities have data on their costs which could enable reasonable estimates of marginal costs. The elasticity of demand depends on applicants' willingness to pay and universities face the same difficulties in estimating this as do conventional firms. They might consider how much students pay for similar programs elsewhere, and it might consider various screening mechanisms of the sort used by airlines, for example, to identify willingness to pay of customers . As is the case for all firms, some information about the demand function will be revealed to the university ex post.

\section{The university's decision rules regarding the fee and the number of fee places.}

The purpose of this section is to develop some rules governing the university's fee and enrolment decisions. These decisions apply to those students who do not receive a HECS place. In the next section we consider the decisions about the size of the HECS premium or 
discount. In most cases the variables that affect the fee also affect the size of the HECS premium or discount in an analagous way.

The analysis in Section 2 is illustrated in Figure 1. This is a base case characterised by the following market conditions:

- The quality of applicants is sufficiently high that it is not a binding constraint on the number of fee places offered;

- the number of applicants is sufficiently high and/or their willingness to pay sufficiently high and/or costs sufficiently low, that the maximum number of fee places allowed is binding.

These conditions currently apply in many high demand/low cost programs in the more prestigious universities in Australia. Examples of such programs are the generic Business/Commerce programs - Bachelor of Business and Bachelor of Commerce.

Point $\mathrm{M}$ is the maximum enrolment that the university would be prepared to accept in order to maintain student quality. The implications for the demand function of the university's concern about student quality are discussed further below and in Section 5. A marginal revenue (MR) curve is associated with the demand curve, $\mathrm{D}$, and marginal cost is denoted MC. The enrolment level that maximises profit is the level at which MR=MC. This occurs at E which equals $\mathrm{H}$ plus the optimal number of full fee-payers, E-H. The fee associated with the optimal enrolment of fee-payers is $f_{e}$; it is the fee that the university would need to charge in order to fill E places. Note however that, by the assumption given above, the maximum allowable number of fee places, $\mathrm{E}^{\mathrm{max}}$, is less than the optimal number, $\mathrm{E}$.

The implications for public policy of the quota on fee places are readily apparent. If the university chooses to charge the fee that the market will bear, $f_{2}$, and thereby avoid excess demand, the fee-paying students are worse off than they would be without the governmentimposed quota on fee places because they would be paying a higher fee. The university is also 
worse off in this case because it is forced to restrict enrolments of fee-payers below the optimal level of $\mathrm{E}-\mathrm{H}$. The third group that is worse off are the $\mathrm{E}-\mathrm{E}^{\mathrm{max}}$ applicants who have achieved cut-off scores that satisfy the university's standards for entry, are willing to pay the market price but cannot gain entry. The latter group have been squeezed out because they scored marginally lower entry scores than those of the E-H applicants. Public policy has arguably failed this group more than the others because they are being denied the opportunity to invest in their human capital on the basis of slightly lower entry scores which the university itself has decided are high enough to indicate a likelihood that they will be able to meet the academic requirements of the course. In support of this, Norton (2002, p.58) cites Australian evidence that differences in student entry scores, over a considerable range, are not reliable indicators of differences in the likelihood of satisfactory completion of a degree. Hence it cannot be argued that the $E-E^{\max }$ applicants would not have been suitable for university education. The quota on fee places is also inequitable because, as indicated above, applicants from lower socio economic backgrounds tend to achieve lower entry scores that are not explained by their lower potential for success at university but to less sophisticated preparation and encouragement for the entry score competition (a range of evidence for this is cited in Norton, 2002, ch.6). This means that these people will tend to be over-represented in the group of $E-E^{\max }$ applicants who miss out on a fee paying place and therefore miss out on the opportunity to invest in their human capital.

Our task is now to see how the following four variables influence the optimal fee and number of fee-payers:

(i) the WTP of applicants

(ii) the number of applicants

(iii) the marginal cost of a student place

(iv) the quality of applicants. 
The effect of each variable is depicted diagrammatically in Figures 2A to D and summarised in Table 1. The examples of particular disciplines given in Figures 2A to D are meant to be plausible but certainly not necessarily applicable in all universities at all times.

Figure 2A illustrates the case where two degree programs have a similar cost structure - for example, Economics and Law - but students are willing to pay more for one, say Law, that the other. This might be because the lifetime earnings for Law graduates is perceived to be greater than that for Economics graduates. The demand curve for Law is therefore vertically above that for Economics. As shown, it is optimal to charge a higher fee for Law, $\mathrm{f}_{2}$, and enrol more fee-payers in Law, $\mathrm{E}_{2}$, than for Economics. The same result emerges where two degree programs have similar costs but the number of applicants is larger in one, even though the willingness of students to pay is no different. This is illustrated in Figure 2B where the demand curve for Business Studies, for example, is horizontally to the right of that for Media Studies. It is therefore optimal to enrol more fee-payers, and at a higher fee, in Business Studies than in Media Studies. In the next case, Figure 2C, two degree programs have the same demand function as a result of a similar number of applicants with similar willingness to pay, but the courses have different marginal costs. Nursing, for example, has higher marginal costs than Psychology, with the result that it is optimal to enrol fewer students but at a higher fee in Nursing than in Psychology.

The final case, Figure 2D, suggests an interesting implication of the university’s concern about applicant quality. The diagram shows three degree programs, each with the same demand and marginal costs but different quality of applicants. In each case, point $\mathrm{M}$ in the diagram indicates the maximum number of applicants that the university is willing to admit in order to maintain minimum academic entry standards. It can be seen that, since demand and costs are assumed to be the same in each case, lower quality can result in fewer applicants being admitted, and at a higher fee. Examples given are Environmental Science and 
Linguistics, where the former is deemed here to have a lower quality of applicants resulting in fewer enrolments and higher fees. It is possible that the academic quality of the applicants is so low that, once the HECS quota has been filled, there are no applicants who meet the minimum entry standards. The example of this situation in Figure 2D is for an Information Technology degree.

Further on the issue of applicant quality, it not only varies among degree programs, but can over time for a given degree program. The trend towards wider participation in higher education has arguably lowered the average quality of applicants for many degree programs. Lower quality for a degree program can also fall as a result of a shift in demand towards other, competing, programs. The demand for Economics degrees, for example, dropped markedly from the 1970s to the 1990s in most countries due, at least in part, to the proliferation of substitute programs. If a drop in demand for a program is associated with lower quality of applicants, the effect on price - that is, the fee - is ambiguous. To see this, consider Figure 3, which illustrates a drop in demand from $D_{1}$ to $D_{2}$. The case where there is no change in the average quality of applicants is represented by a proportional shift to the left in point $M$ from $M_{1}$ to $M_{2}$. The result is a lower fee, $f_{2}$ (the $M R$ and $M C$ curves are suppressed to simplify the diagram). It is possible, however, that the drop in demand comes from the better students resulting in a lower average quality of applicants. This is illustrated by a shift to the left in point $M$ from $M_{1}$ to $M_{3}$ which is sufficent to result in a higher optimal fee. This runs counter to the normal expectation that a drop in demand for a product leads to a lower price, other things constant and given an upward sloping supply function.

The source of this apparently anomalous result is the university's concern about the quality of its students. The concern about quality is discussed further in Section 5, where it is shown to have significant implications for the demand function for student places. 


\section{The university's decision rules regarding the HECS premium.}

The decision rules governing the optimal HECS premium are analagous to those for the optimal fee. In other words, "fee" in the above four scenarios can be replaced by "HECS premium”. However these decisions are separate in the sense that decisions about whether to charge a HECS premium, and the size of the premium, have no necessary implications for whether to enrol full fee-paying students and the size of the fee, and vice versa. This is discussed further in the next section.

This section illustrates the analagy between decisions about the HECS premium and the fee with reference to Figures $4 \mathrm{~A}$ to D. The horizontal axis represents the number of HECS places and starts from zero because HECS places are allocated before full fee places. The vertical axis measures the HECS charge. The term "HECS" on the vertical axis represents the standard HECS charge for a discipline and $\mathrm{HECS}_{\max }$ is the maximum allowable HECS charge which, under the new legislation in Australia, is 25 percent above the standard HECS charge. The HECS quota is denoted by $\mathrm{H}$. This quota is negotiated between the university and the government. Hence the university does not have full control over this variable and therefore cannot necessarily set $\mathrm{H}$ at the optimal level, which is at the point where the $\mathrm{MC}$ equals the MR of the last HECS place. Because $\mathrm{H}$ is not set strictly where MC=MR, these curves are suppressed for simplicity in Figure 4. Nevertheless, the university will have regard to its MC and MR when negotiating $\mathrm{H}$, so MC and MR are not irrelevant. To reflect this, Figures 4 is drawn so that a higher demand for a course results in a higher level of $\mathrm{H}$, which reflects a higher optimal H.

Figures 4 show that the outcomes for the HECS charge are analagous to those for the fee. In Figure 4A, for example, a higher WTP of applicants for a Law degree implies a higher HECS charge for Law than for Economics. In fact the HECS charge for Law is at the maximum allowable level - and as the diagram shows, students would in fact be prepared to 
pay more than the maximum. For Economics, the HECS charge is in between the base level and the maximum - hence the premium is less than 25 percent. Figure $4 \mathrm{~B}$ illustrates the possibility that the university will offer a discount for a degree program in which demand is weak, the example being Asian Studies in the diagram. Figure 4C shows that a high cost degree, Nursing being the example, commands a higher HECS charge than does a lower cost program such as Psychology. And, finally, Figure 4D illustrates the case where, for a given demand, a lower quality can imply a higher HECS charge in the same way as it can imply a higher fee for fee-paying students. The three examples given, ranked in order of applicant quality, are Sport Management, Education and Law.

\section{Separation of decisions about the HECS premium and the fee.}

The purpose of this section is to explain why the decisions about the optimal HECS premium and the optimal fee are separate, which implies that it can be optimal to enrol full fee-payers even though the university does not charge the full HECS premium. This is fundamentally because the university cares about the quality of its students.

Unlike the firm in the traditional microeconomic model, universities care about the quality of their customers, who are their students ${ }^{5}$, not just about their willingness to pay (Winston, 1999). They care about the quality of their students for at least two reasons. One is that high quality students, and therefore graduates, enhance the prestige and reputation of the university. The other is that, in the classroom, peer quality is an important input into the learning process for all students. In other words, high quality students improve the learning experience for other students. This concern about customer quality as well as willingness to pay, means that the traditional model of the price/output decision of the firm must be modified in applying it to fee/enrolment decision of the university.

\footnotetext{
${ }^{5}$ One could argue that the ultimate "custoomers" of universities are the end users of the human capital embodied in graduates - the end-users being the employers who hire the graduates. The author is grateful to an anonymous referee for pointing this out.
} 
In practice, universities use the student entry score as a proxy for student quality. They effectively rank all of the applicants for a given degree program in descending order of entry score. The number of HECS-funded places, $\mathrm{H}$, negotiated with the Government, are offered to applicants on a highest entry score first basis. An important constraint on $\mathrm{H}$ is that student quality must be maintained by, in practice, setting a cut-off score below which applicants are denied entry to the degree program.

Consider Table 2 which shows the entry score and willingness to pay (WTP) of a hypothetical cohort of 30 applicants for a degree program, sorted by their WTP. It is assumed that there are no other applicants. It is also assumed that the lowest entry score, 75 , is above the minimum score deemed acceptable by the university. There is no obvious correlation between entry score and willingness to pay in Table 2. This is evident from Figure 5 which plots each person's WTP and entry score. In fact, for these hypothetical data, the correlation coefficient between the two variables is 0.25 which is statistically no different from zero for this sample size.

What does the demand function look like for these data? The demand function defines the number of eligible applicants willing to pay each fee level. However, there are two groups of eligible applicants: those who are selected to fill the HECS quota and those who are offered full fee places. The former group are selected by ranking all applicants according to their entry score, from high to low, and offering HECS places from the top of the list until the quota is filled. Suppose that the university has a HECS quota of 20 places. It would fill these places by taking the top 20 applicants ranked by entry score. ${ }^{6}$ As Table 2 indicates, these would not be the top 20 applicants ranked by WTP. Rather, the WTP of the top 20 applicants ranked by entry score is plotted in Figure 6 and labelled "WTP - HECS places”. Full fee places could then be offered to the remaining applicants subject to the quota. The WTP of

\footnotetext{
${ }^{6}$ The process of multiple round offers to applicants is ignored. The outcome described here is the final outcome after all offers have been made and processed.
} 
these applicants is also plotted in Figure 6 and labelled "WTP full fee places". The effective demand function facing the university is a composite of the demand functions for the HECS funded applicants and the full fee paying applicants. There is a vertical discontinuity in this function at the point where the HECS quota is filled and the full fee places begin - that is, at point $\mathrm{H}$. The exception is the special, and highly unlikely, case in which there is a perfectly positive positive correlation (a coefficient of 1 ) between WTP and entry score, in which case there would be no vertical discontinuity. Rather the demand function would be continuous. This special case is shown in Figure 6 and labelled "WTP-all applicants".

Hence the university's concern about student quality creates a discontinuity in the demand function at point $\mathrm{H}$. The degree of discontinuity depends on the correlation between WTP and entry score. There is no direct empirical evidence on the correlation between these variables. There are many studies examining the effect of tuition fees on enrolment - for a recent paper see Berger and Kostal (2002) and for an earlier survey see Leslie and Brinkman (1987). These studies find overwhelmingly that tuition fees have a significant negative effect on enrolment demand. Hence they say something about willingess to pay but not about the link between willingness to pay and the scholarly aptitude of applicants which is measured in Australia by their entry scores. This evidence does not indicate, for example, whether highentry-score students have a greater willingness to pay than low-entry-score students. Perhaps some inference, at least for Australia, can be drawn from the evidence cited in Norton (2002) that students from low socio-economic backgrounds tend to have lower entry scores. If lower socio-economic background suggests low WTP then the evidence cited by Norton points to a positive correlation between WTP and entry scores. In support of this, one could imagine that people who have a high desire to attend university might work hard at school, achieve a high entry score and have a high WTP. On the other hand, wealthy people who do not rely as much on a university degree as a path to financial rewards, might have a high WTP due to their high 
capacity to pay, but a low entry score because they have not worked as hard for a university place. For these people the correlation between WTP and entry score would be negative.

Therefore, it seems reasonable to assume that there is less than perfect positive correlation between WTP and entry score, in which case there is a vertical discontinuity in the demand function.

Finally, the vertical discontinuity in the composite demand function allows us to illustrate another implication of the new funding system. This is done with the aid of Figure 7 which combines the diagrammatic analysis of the decisions for HECS-paying and full feepaying students in a single diagram. $\mathrm{D}_{\mathrm{h}}$ is the part of the composite demand function that applies to HECS-payers and $\mathrm{D}_{\mathrm{f}}$ is the other part of the composite demand and applies to full fee-payers. Given $\mathrm{H}$, the level of HECS that the market will bear is $\mathrm{HECS}_{1}$ which is less than the maximum allowable HECS premium (which, in the new legislation, is 25 percent above the standard HECS level, labelled "HECS" in the diagram as in Figures 4). The level of demand in Figure 7 has been drawn in order to illustrate an implication of the vertical discontinuity in the composite demand function. That is, in this scenario it is optimal to offer full fee places even though the full HECS premium is not being charged. This seems to be counter to the popular perception that universities would only offer full fee places if they were charging the full HECS premium.

\section{Conclusion: implications for university policy and public policy.}

This paper has presented a framework for analysing the university's fee end enrolment decisions for undergraduate places under the new legislation to take place from the start of the 2005 academic year in Australia. The analysis is relevant to other countries because, as indicated in the introduction, the income contingent loan scheme called which was pioneered in Australia, where it is called HECS, has been either adopted or recommended for adoption 
in a range of other countries including the U.K. and the U.S. The framework adpted to illustrate this scheme integrates student demand, marginal costs, the role of entry scores as an allocative mechanism, the constraint arising from the negotiated number of HECS places, and the effect of the quality of applicants given a minimum acceptable standard. All of these factors come into play in decisions about the optimal HECS charge, the optimal number of full fee paying places and the associated fee level.

The analysis yields several policy implications for universities and government, some of which have not been widely anticipated in discussions of the new system. A number of situations can be identified in which the university may not wish to enrol the maximum number of full fee-paying places: demand may be insufficient, the quality (proxied by the entry score) of the marginal student may be too low, or costs may be too high. The analysis has also shown that a decision to enrol full fee paying students does not necessarily imply that the maximum premium on HECS places will be charged. Another possibility is that a drop in demand for a degree program could lead to higher, rather than lower, student fees, if the lower demand is associated with a much lower quality of applicants.

There are strong implications for public policy with regard to the quota on fee-paying places. In disciplines such as business where demand is strong and costs are low, the quota on fee-paying places is likely to be binding. The quota restriction was shown to be poor public policy on both efficiency grounds, since both university and all students are worse off, andequity grounds since applicants who miss out on a place are likely to come disproportionately from low socio-economic backgrounds. 


\section{References}

Berger, M. and Kostal, T. (2002) "Financial Resources, Regulation, and Enrollment in US Public Higher Education”, Economics of Education Review 21, 101-110.

Chapman, B. (2004) “A Critical Appraisal of the New Higher Education Charges for Students”, Dialogue 23, 1, 61-72.

Leslie, L. and Brinkman, P. (1987) “Student Price Response in Higher Education: the Student Demand Studies”, Journal of Higher Education 58, 181-204.

Norton, A. (2002) The Unchained University, The Centre for Independent Studies, Policy Monograph 56, Sydney.

Varian, H. (1999) Intermediate Microeconomics, $5^{\text {th }}$ Edition, Norton, New York.

Winston, G. (1999) “Subsidies, Hierarchy and Peers: The Awkward Economics of Higher Education”, Journal of Economic Perspectives, 13, 1, 13-36 


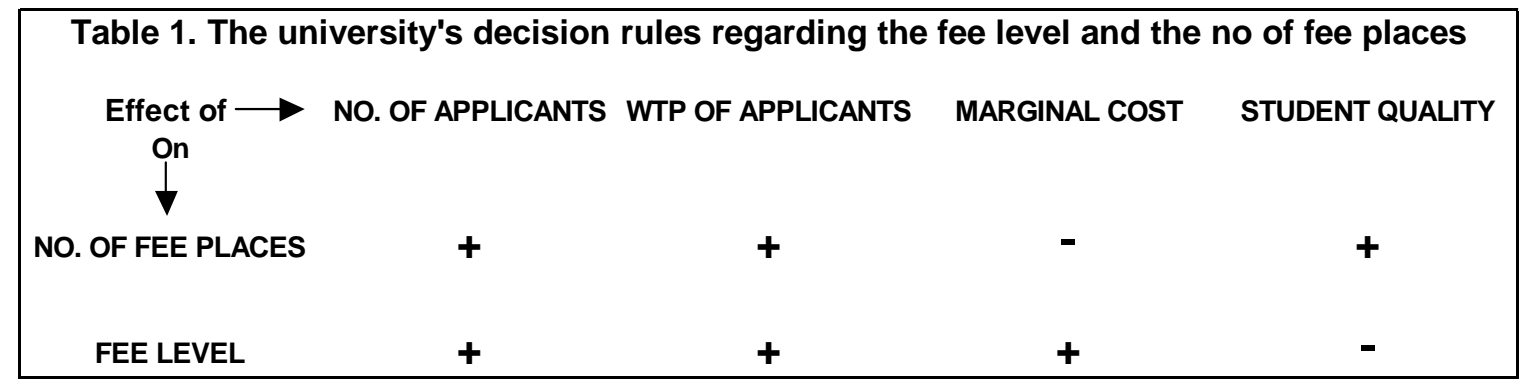

Table 2. Willingness to pay (WTP) and entry scores of a hypothetical cohort of $\mathbf{3 0}$ applicants for a given degree program

\begin{tabular}{ll|ll} 
Student no. WTP entry score & Student no. WTP entry score
\end{tabular}

\begin{tabular}{lll|lll}
1 & 100 & 85 & 16 & 85 & 85 \\
2 & 99 & 86 & 17 & 84 & 84 \\
3 & 98 & 86 & 18 & 83 & 81 \\
4 & 97 & 60 & 19 & 82 & 93 \\
5 & 96 & 75 & 20 & 81 & 94 \\
6 & 95 & 91 & 21 & 80 & 95 \\
7 & 94 & 64 & 22 & 79 & 72 \\
8 & 93 & 63 & 23 & 78 & 72 \\
9 & 92 & 87 & 24 & 77 & 75 \\
10 & 91 & 78 & 25 & 76 & 76 \\
11 & 90 & 79 & 26 & 75 & 69 \\
12 & 89 & 75 & 27 & 74 & 68 \\
13 & 88 & 91 & 28 & 73 & 68 \\
14 & 87 & 69 & 29 & 72 & 76 \\
15 & 86 & 70 & 30 & 71 & 75 \\
\hline
\end{tabular}


Figure 1. The base case

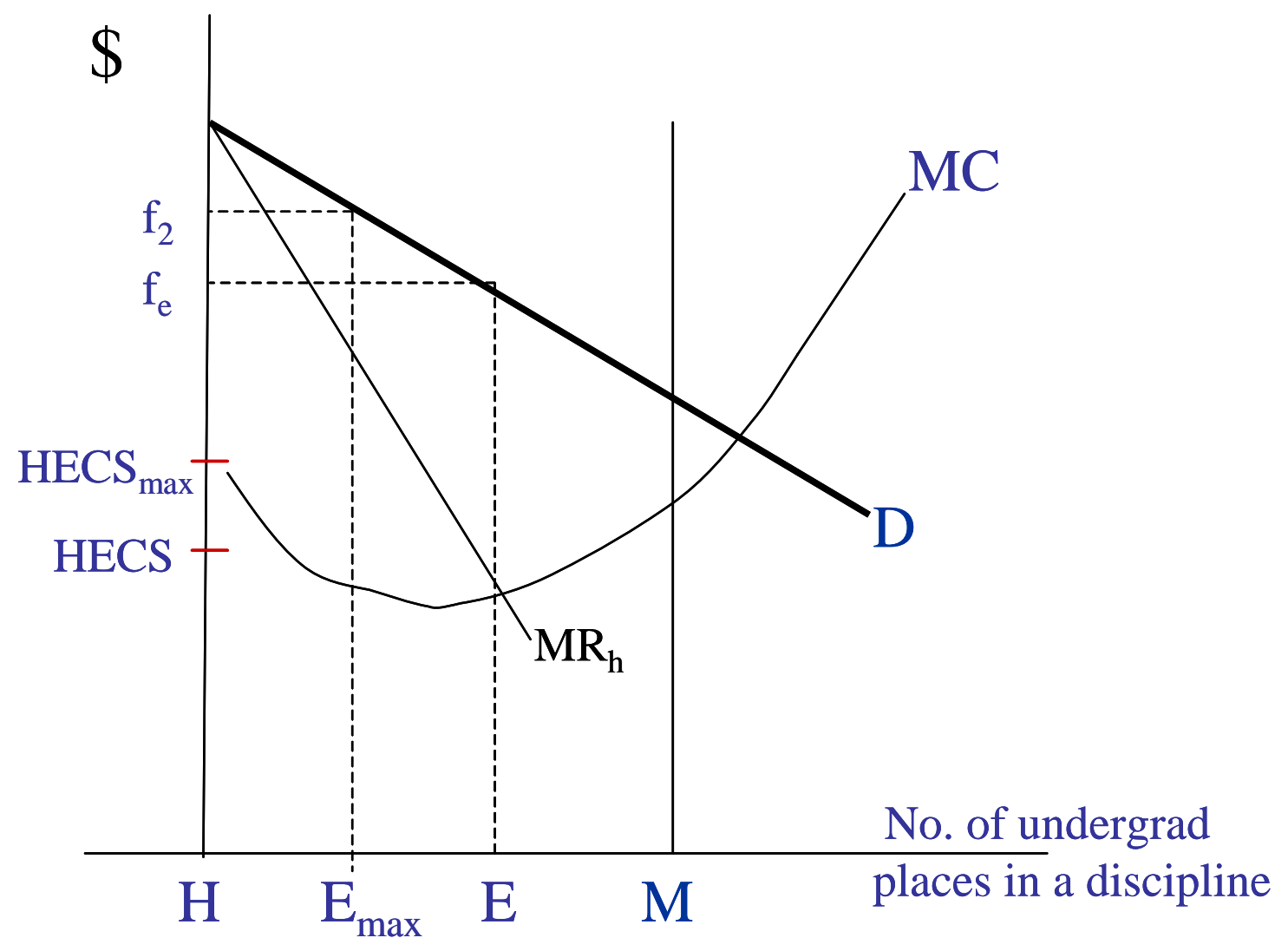


Figures 2. Decision rules for fees and enrolments of fee-payers

\section{A. Effect of WTP}

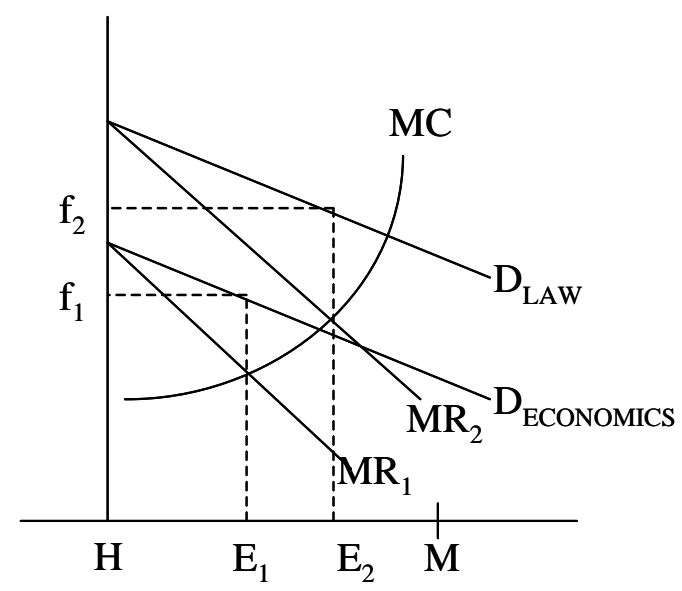

C. Effect of marginal cost

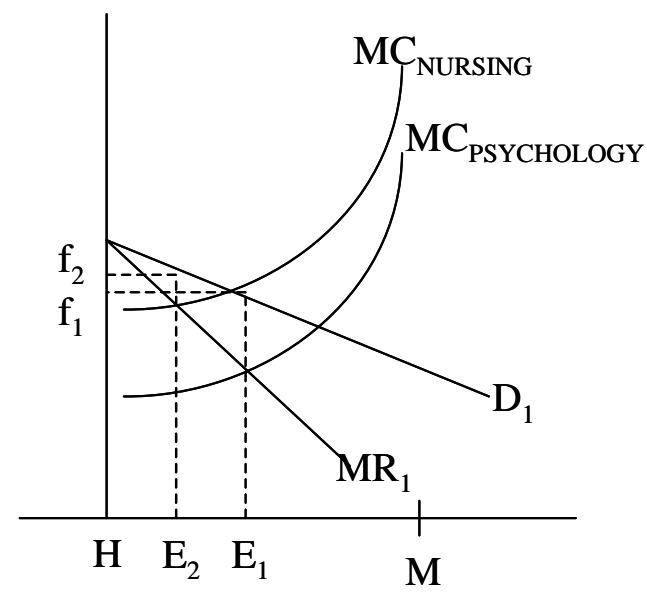

B. Effect of no. of applicants

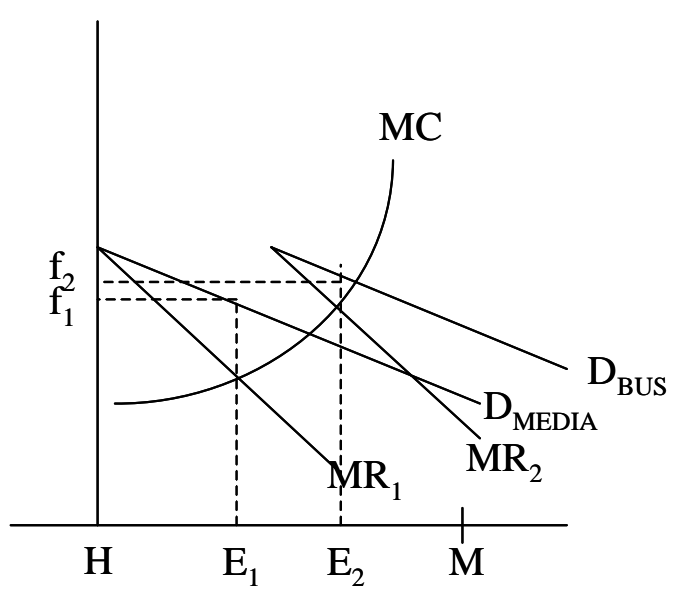

D. Effect of binding applicant quality

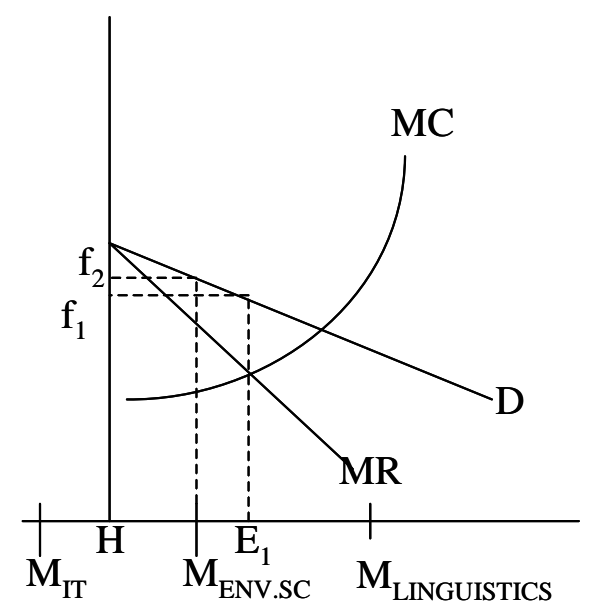


Figure 3. The effect of demand and lower quality.

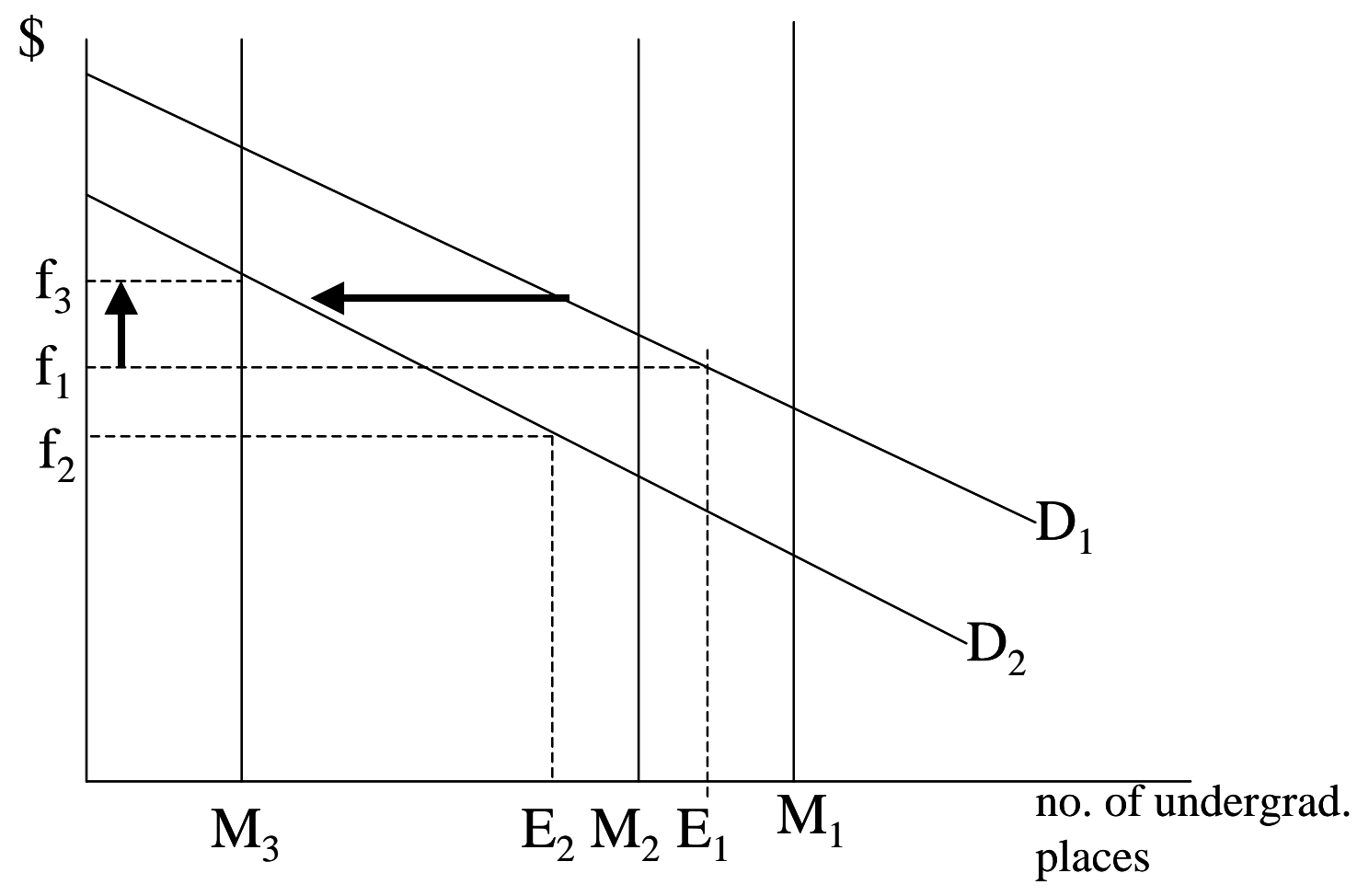


Figures 4. Decision rules for HECS premium

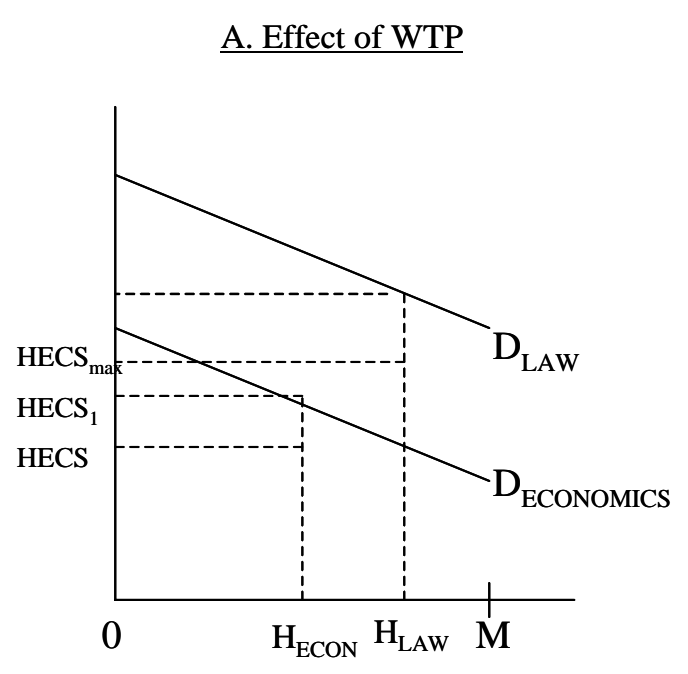

$\underline{\text { C. Effect of marginal cost }}$

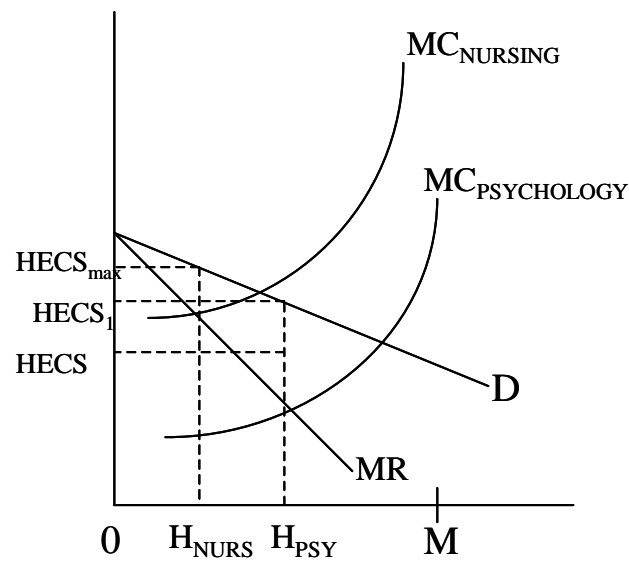

B. Effect of no. of applicants

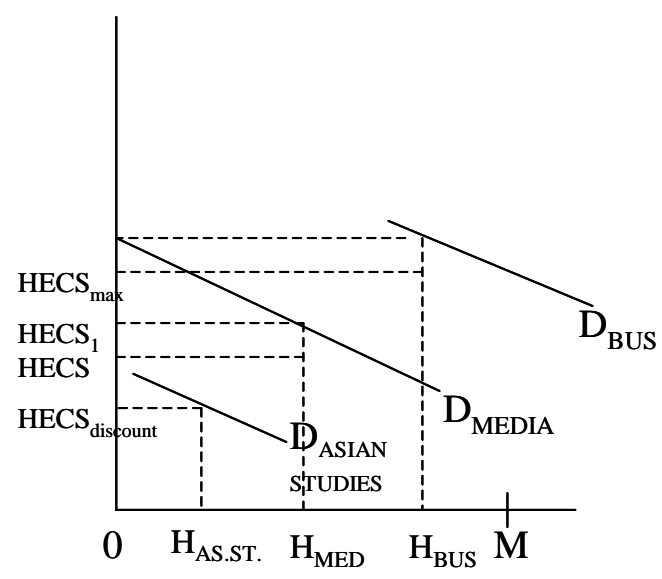

D. Effect of binding applicant quality

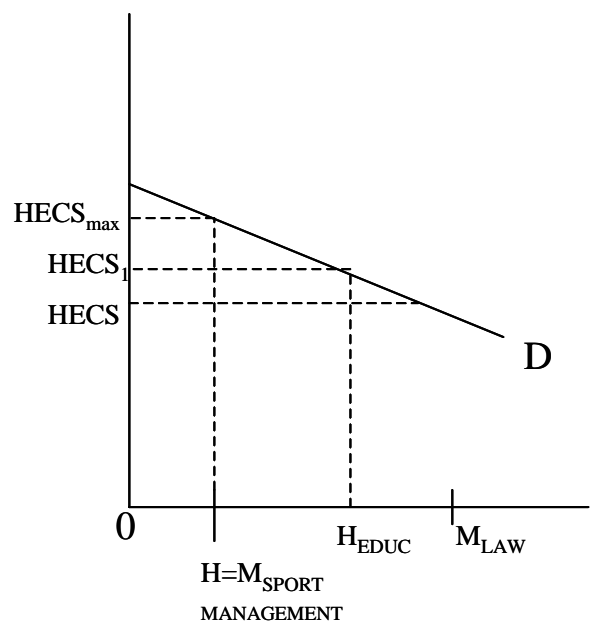



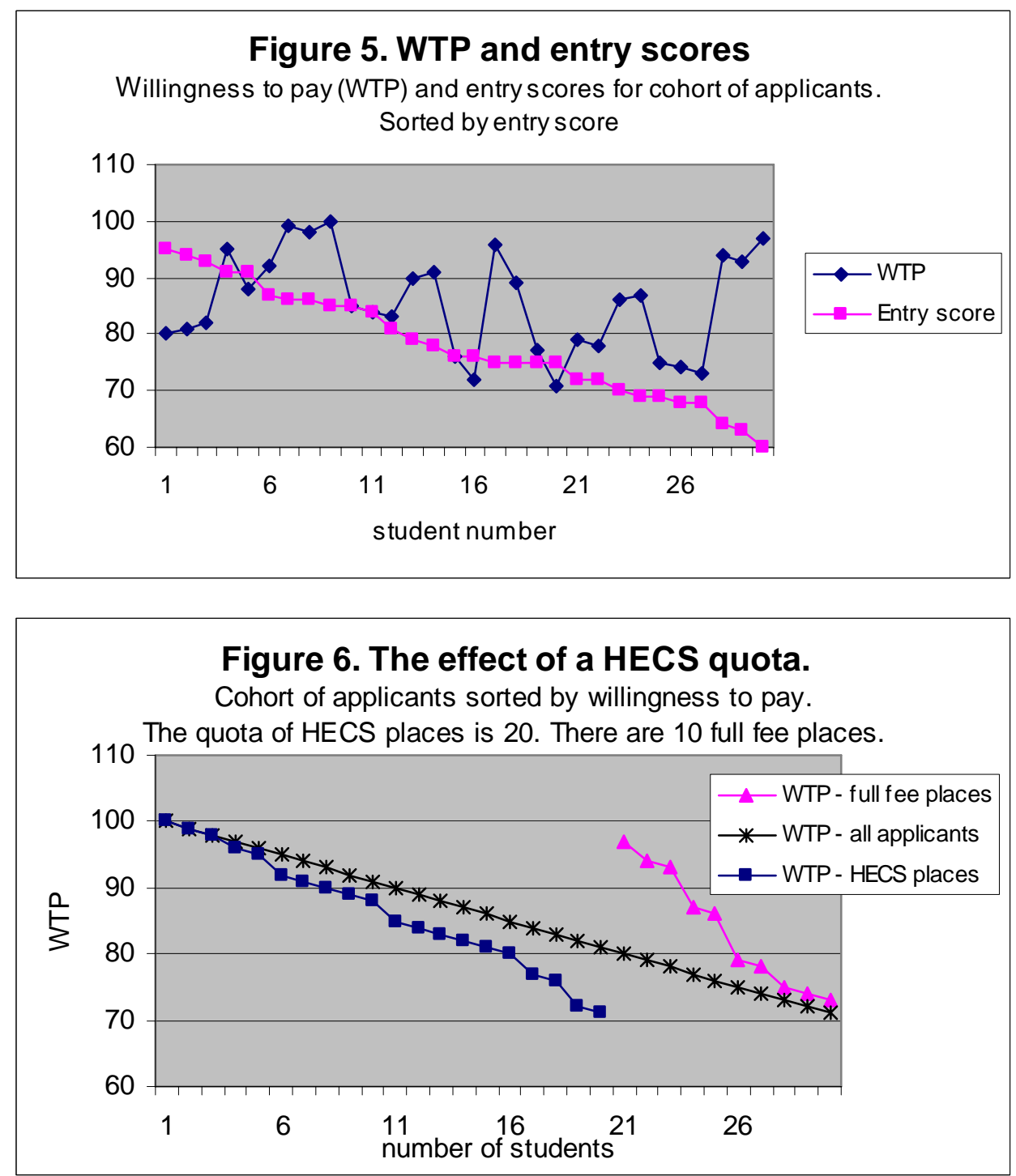
Figure 7. The composite demand function for the base case.

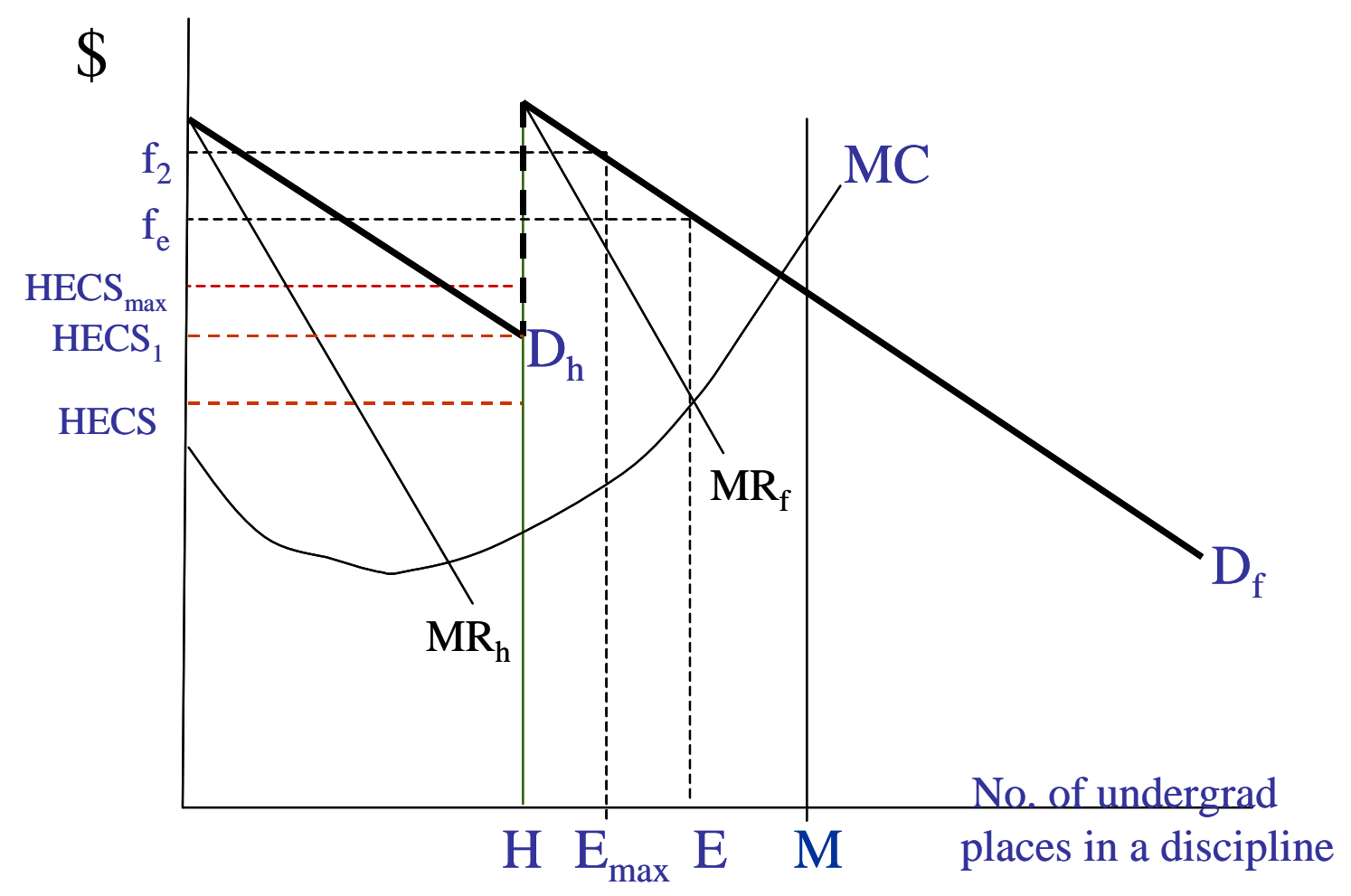

